\title{
ОСНОВНЫЕ ПОДХОДЫ К ОБЕСПЕЧЕНИЮ СБАЛАНСИРОВАННОСТИ ИНТЕРЕСОВ УЧАСТНИКОВ ФАНДРАЙЗИНГОВОЙ ДЕЯТЕЛЬНОСТИ НКО
}

\author{
(c) 2019 Басова Мария Михайловна \\ кандидат экономических наук, доцент Департамента учета, анализа и аудита \\ Финансовый университет при Правительстве Российской Федерации, Россия, Москва \\ E-mail:MMBasova@fa.ru
}

В статье рассматриваются основные подходы фандрайзера к работе с различными группами стейкхолдеров некоммерческой организации с целью обеспечения сбалансированности их интересов. Показано, что для осуществления эффективной фандрайзинговой деятельности некоммерческие организации должны наладить четкие, обоюдно выгодные отношения со всеми заинтересованными лицами, основанные на выявлении интересов и ожиданий последних.

Ключевые слова: фандрайзинг; фандрайзер; стейкхолдеры; НКО; фандрайзинговая деятельность; доноры, благополучатели; социальный проект.

В современных условиях практически перед каждой некоммерческой организацией стоит ряд непростых задач. Каждая организация стремится быть полезной своей целевой аудитории, уверенной в необходимости и эффективности деятельности, а также иметь хорошую репутацию и достаточное количество ресурсов.

«Одной из основных функций управления некоммерческой организации (далее НКО) является фандрайзинг, который можно рассматривать, как сложный процесс по привлечению финансовых и нефинансовых ресурсов для своей деятельности. Фандрайзинг как функцию управления можно рассматривать как деятельность по привлечению денежных средств и иных ресурсов (материальных, человеческих, информационных и т.д.) из всех возможных каналов и источников финансирования на некоммерческие цели (реализацию определенного проекта или в целом своей деятельности), которые некоммерческая организация не может обеспечить самостоятельно» [2].

Однако, в настоящее время для большинства НКО России существует серьезная проблема недостаток финансовых средств для реализации социальных проектов и программ, обусловленная трудностью их получения. В этих условиях некоммерческие организации вынуждены заниматься поиском и привлечением источников финансирования. Для успешного привлечения финансовых и нефинансовых ресурсов во всем мире используется технология фандрайзинга.

Задача любого фандрайзера сводится к росту числа потенциальных спонсоров и благотвори- телей. Для этого в своей деятельности он должен широко использовать современные методы привлечения денежных средств и других ресурсов; систематически проводить анализ рынка доноров; разрабатывать системы привилегий для доноров; выявлять интересы доноров, их ожидания и претензии к некоммерческой организации.

Фандрайзер должен понимать, что давать деньги доноры предпочитают успешным, ибо успешность организации является залогом грамотного использования благотворительных пожертвований. Чтобы быть такой уважаемой и благополучной, конечно же нужно предпринять некоторые усилия. В этой связи с самого начала построения системы партнерства с бизнесом и обществом руководство НКО должно задуматься о формировании своей репутации. Чем НКО известнее, тем с меньшими препятствиями достигает своих целей.

Следует помнить, что баланс возможных поступлений и расходов НКО во многом зависит от масштабов ее деятельности и круга возможных стейкхолдеров, с которыми будет вестись работа. К организации должно возникнуть доверие, а оно появляется, когда компания открыта и прозрачна, когда информация о достижениях доступна любому, кто захочет что-то узнать о НКО. Именно на эту цель в первую очередь работает регулярный, достоверный отчет о деятельности некоммерческой организации, содержащий основную информацию как о самой организации, так и о результатах ее деятельности за определенный период. Обычно это - ежегодный, со- 
держательный отчет НКО, который в последнее время становится все более востребованным у настоящих и потенциальных доноров, к которым некоммерческая организация обращается или будет обращаться за финансовой поддержкой.

Для осуществления эффективной фандрайзинговой деятельности НКО должны наладить четкие, обоюдно выгодные отношения со всеми заинтересованными лицами, которые могут - положительно или отрицательно, прямо или косвенно, повлиять на процесс привлечения финансовых и нефинансовых средств. Как показывает практика, эффективность получения финансовых и нефинансовых средств для реализации благотворительных проектов и программ определяется уровнем развития отношений НКО с государством, местными сообществами, администрациями регионов, коммерческими организациями, частными лицами и сотрудниками компании. Высокий уровень развития отношений, являющийся мощным источником решения социальных проблем, предполагает налаживание конструктивного взаимодействия между заинтересованными сторонами, обеспечение оптимального согласования интересов всех сторон. Очень важно при этом, что бы стейкхолдеры знали, понимали и одобряли деятель- ность НКО.

Благодаря партнерским отношениям с бизнесом, бюджетными учреждениями, властью и средствами массовой информации НКО удается масштабно реализовывать свои программы и проекты в условиях ограниченности собственных ресурсов. К основным формам партнерства в фандрайзинговой деятельности можно отнести: благотворительные акции и совместные проекты, информационные обмены, финансовую и нефинансовую поддержку (предоставление оборудования, помещений), гранты, финансируемые на конкурсной основе и др.

Основной целью фандрайзинга является объединение разрозненных ресурсов и представление их для поддержания уже разработанного проекта или его проекта. Российское законодательство на сегодня предусматривает ряд источников внешнего финансирования «третьего сектора»: президентские, региональные и муниципальные гранты, частные пожертвования, а также донорская помощь от более крупных фондов и НКО. На рисунке 1 приведены формы содействия основными стейкхолдерами (власть, бизнес, частные лица) фандрайзинговой деятельности НКО.

Широко распространенным инструментом бизнес анализа, который целесообразно исполь-
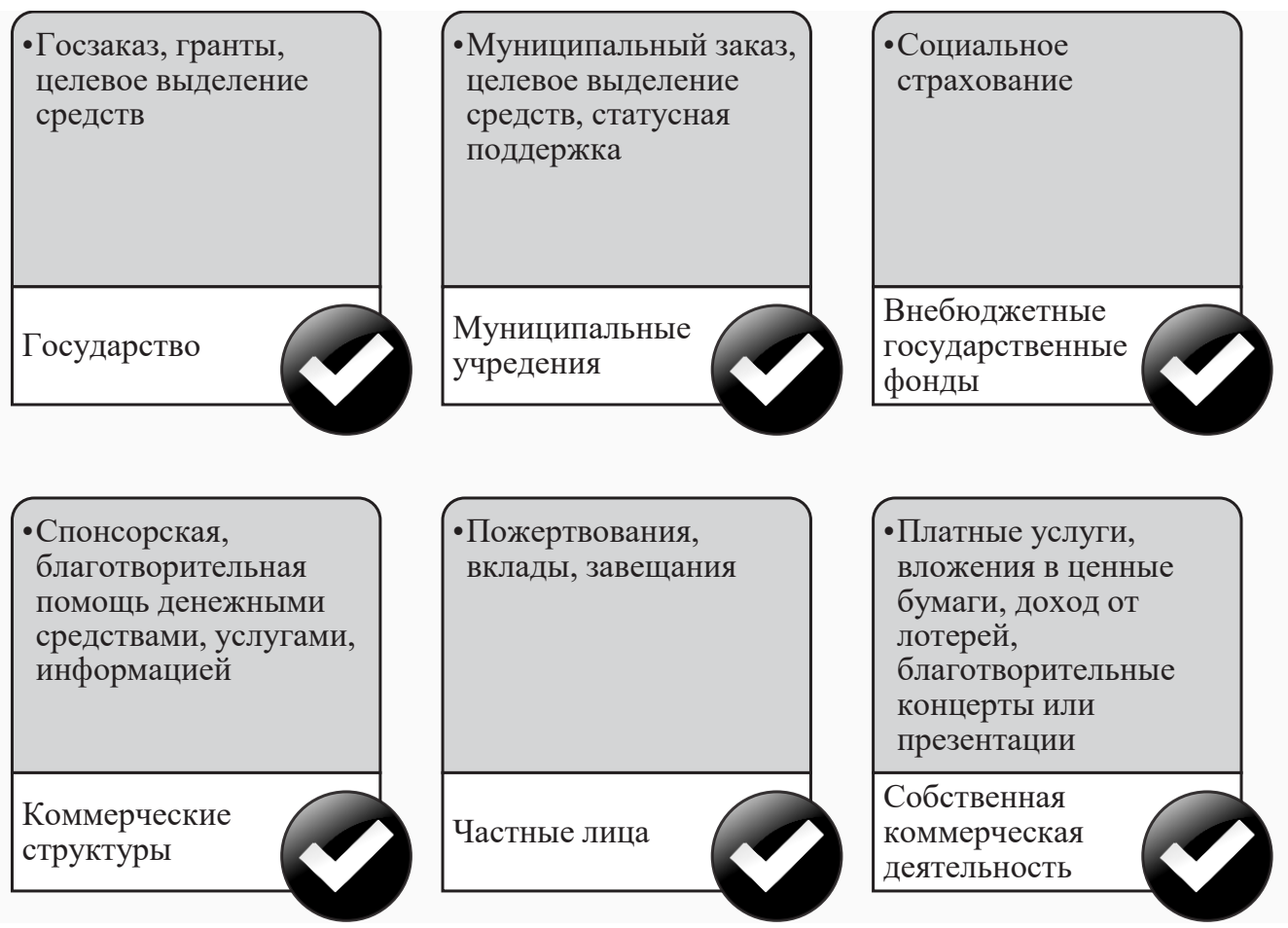

Puc. 1. Основные формы содействия заинтересованными сторонами фандрайзинговую деятельности НКО 
зовать в фандрайзинговой деятельности НКО, является анализ стейкхолдеров, который позволит определить основные заинтересованные стороны в фандрайзинговой деятельности организации, а также изучить предпочтительные направления взаимодействия с ними. Анализ стейкхолдеров необходим для ответа на следующие вопросы: что НКО может получить от них (степень их вклада в работу НКО), каковы их требования и ожидания, какова степень потенциального влияния, которое окажет на них некоммерческая организация.

Интересным примером определения основных групп заинтересованных сторон, на наш взгляд, является выделения трех уровней стейкхолдеров в фандрайзинговой деятельности БФ «Система» [8]:

Стейкхолдеры, которые формируют основу фандрайзинговой деятельности организации: благополучатели, государство, коммерческие структуры, органы муниципального управления, внебюджетные фонды, собственная коммерческая деятельность, частные лица;

1. Заинтересованные стороны, которые оказывают существенное влияние на фандрайзинговую деятельность организации и формирующие ее стратегические задачи, но не имеющие на нее прямого воздействия: общество, СМИ, социальные партнеры;

2. Стейкхолдеры, которые заинтересованы в БФ «Система», но не оказывающие влияния на ее фандрайзинговую деятельность: поставщики, подрядные организации и др.

Взаимоотношения со стейкхолдерами является очень сложным процессом в фандрайзинговой деятельности НКО. Важным на этом этапе является грамотное общения с выбранной группой стейкхолдеров, понимание их ожиданий и контроль за достижением ожиданий. При этом стоит помнить, что разные ожидания - это нормальное явление, но наличие противоположных - является большим риском для достижения запланированных результатов.

Приоритетом работы НКО по фандрайзингу является выявление ожиданий заинтересованных сторон и изучение мотивов их благотворительной деятельности с целью удовлетворение их интересов. В этой связи необходимо постоянно изучать их интересы и потребности, например если им необходим пиар, то это нужно принять во внимание руководителям и сотрудникам НКО. В настоящее время наиболее остро стоит проблема совместного выявления интересов доноров, как между собой в части финансирования деятельности некоммерческой организации, так и непосредственно с НКО с учетом пожеланий благополучателей.

Работа с благополучателями построена по системе обратной связи и, как правило, регулируется внутренними положениями НКО (благотворительного фонда). С целью надлежащего качества реализации программ и своевременного реагирования на изменение ключевых тенденций сектора благотворительности НКО должна регулярно принимать участие в профессиональных событиях и публичных встречах с экспертным и профессиональным сообществами, представителями общественных, государственных организаций и СМИ. Все материалы о значимых событиях и результатах фандрайзинговой деятельности НКО в обязательном порядке должны публиковать на собственном веб-сайте, в собственных корпоративных изданиях, размещаются в базах новостных и информационных агентств.

Приведем пример. Всероссийский благотворительный фонд «Фонд продовольствия «Русь» [9] является примером того, как НКО, общественность, бизнес и власть могут действовать сообща для решения социальных проблем территории. Фонд собирает продукты питания и товары первой необходимости на бесплатной основе от российских производителей, кафе, ресторанов, магазинов и передает еду социально незащищенным категориям населения во всех регионах Российской Федерации. Распределение помощи фонд организует через приходы Русской Православной Церкви, социальные службы, и частные некоммерческие организации.

Основная цель государственной благотворительности заключается в обеспечении приемлемого уровня жизни для тех категорий населения, которые в силу тех или иных причин не могут самостоятельно реализовать свои социальные права. К этой категории граждан можно отнести: безработных, инвалидов и иных лиц, которые в силу своих физических или интеллектуальных особенностей, иных обстоятельств не способны самостоятельно реализовывать свои права и законные интересы; население пострадавшее в результате стихийных бедствий, экологических, промышленных или иных катастроф и др. Образ благополучателя, как его называет Всероссийский благотворительный фонд «Фонд про- 
довольствия «Русь» складывается из социально незащищенной группы людей, которым не хватает денежных средств на приобретение самого необходимого. Как правило, это все известные категории населения: многодетные и малоимущие семьи, семьи с детишками-инвалидами, неполные семьи и, конечно же, пожилые люди, которые далеко не всегда могут помочь себе сами, особенно если они оказались одни, без детей и близких родственников.

Для органов государственной власти и местного самоуправления партнерство с НКО и бизнесом позволяет оптимизировать ресурсы, а также иметь возможность за счет эффективного использования ресурсов, которыми владеет некоммерческий сектор, осуществлять адресную поддержку целевой аудитории или проекта без создания или использования каких-либо государственных учреждений. Государственные организации и ведомства финансируют в первую очередь те социальные проекты, которые они не всегда могут выполнить своими силами, и по результатам тендеров или конкурсов распределяют бюджетные средства на федеральном, региональном и местном уровнях, а НКО средства выделяются в виде субсидий, грантов или госзаказа. Приведем пример. Государственное финансирование и поддержка Фонда продовольствия «Русь», как банка еды и продовольствия, на практике его называют продовольственным банком, частично снижает трудности правительства по устранению «пищевой бедности», связанной с уровнем доходов населения За рубежом развитие продовольственных банков позволяет снижать количество пищевых отходов, и освобождает правительство от ответственности за продовольственную безопасность, перенося обязательства на сектор пищевого производства Выгода от такого партнерства для НКО включает повышение доверия со стороны органов власти; дополнительные возможности для реализации миссии; улучшение ресурсного обеспечения и др.

Органы власти понимают, что те вопросы, которые задаются, это актуально, серьезно, важно для людей. Местное сообщество, вовлекаясь в проект, также является одним из участников партнерства, получает в качестве выгоды решение проблем, улучшение качества жизни и т.п. Городу, местным властям также достаточно очевидно, что развитие местного сообщества, развитие коммуникаций, развитие возникающего межсекторного диалога означает формирова- ние в городе благоприятной среды. С точки зрения экономии государственных ресурсов, это уменьшение издержек, целевое распределение средств, плюс повышение уровня доверия и авторитета власти, улучшение взаимопонимания.

Например. 27 апреля 2017 года в Барнауле, Фондом продовольствия «Русь» на базе регионального отделения общероссийской общественной организации «Российский Красный Крест» был запущен проект «Народный обед», в рамках которого нуждающимся и людям, попавшим в трудную жизненную ситуацию, выдают продовольственную продукцию. Цех по фасовке продуктовых наборов открылся в помещении организации, которое передано администрацией города Барнаула на условиях безвозмездной аренды до конца 2018 года.

Для тиражирования социального проекта или программы некоммерческим организациям нужно уметь сотрудничать с местной властью, а также производить важные для общества по содержанию и интересные по форме мероприятия. Например, 28 апреля 2017 года в управлении Алтайского края по пищевой, перерабатывающей, фармацевтической промышленности и биотехнологиям состоялась встреча представителей Фонда продовольствия «Русь» и Алтайского регионального отделения Общероссийской общественной организации «Российский Красный Крест» и руководителей ведущих предприятий по производству мукомольной продукции. Целью встречи стало обсуждение перспектив сотрудничества по поставкам алтайского продовольствия в рамках гуманитарных проектов Фонда «Русь». Представители предприятий выразили заинтересованность в сотрудничестве с Фондом и заявили о готовности участвовать в конкурсных процедурах на поставку всех видов продукции зернопереработки в рамках гуманитарных проектов фонда «Русь».

Коммерческие организации - юридические лица, которые могут направлять на благотворительные программы часть своих денежных или неденежных ресурсов. Приведем пример сотрудничества бизнеса с некоммерческими организациями. Фонд продовольствия «Русь» сотрудничает с производителями товаров, торговыми сетям, ресторанами, финансовыми организациями. X5 Retail Group (бренды «Пятерочка», «Перекресток», «Карусель») стал первым партнером Фонда среди розничных сетей в области продажи, сбора, упаковки и распределения 
продовольственной помощи среди малообеспеченных семей, запустив федеральный проект по оказанию продовольственной помощи социально незащищенным категориям населения. Он не только принимает излишки продукции, но также организует различные акции, в том числе с вовлечением корпоративных волонтеров по всей стране, а также акции по сбору пожертвований на спасение продовольствия. Супермаркеты предоставляют излишки съедбной продукции благотворительным организациям, а не выбрасывают их. Для пищевых корпораций и крупных пищевых ретейлеров передача ненужных съедобных продуктов создает благоприятный имидж: снабжая продовольственные банки, они помогают прокормить нуждающихся и одновременно снижают свой экологический риск.

В России компании выделяют благотворительные пожертвования из чистой прибыли. Известно, что в российской практике компании иногда расходуют на поддержку НКО средства из бюджетов отделов рекламы, маркетинга или работы с персоналом. У бизнеса есть три основных мотива, по которым они готовы выделять ресурсы на социальные программы: личные мотивы руководителя, который принимает решение и социальные и коммерческие выгоды.

Коммерческие выгоды для компании: возможность снижения налогового бремени, стимулирование продаж, вывод на рынок нового товара или услуги через повышение узнаваемости и лояльности.

Традиционно представители бизнеса видят следующие социальные выгоды.

1. Укрепление репутации компании как социально ответственной организации среди стейкхолдеров: клиентов, партнеров, государства и других.

2. Повышение лояльности и мотивация сотрудников компании; развитие корпоративной культуры, в т.ч. через привлечение сотрудников к системной благотворительности, создание атмосферы творчества, социальной активности;

3. Моральная поддержка со стороны государства и общества.

Ключевым моментом перехода к партнерским отношениям бизнеса и НКО является понимание партнерами мотивов и потребностей друг в друге. Так, X5 Retail Group предоставляет свои магазины для проведения акций, формат которых напрямую связан с профильной деятельностью Фонда продовольствия «Русь» (сфе- рой потребления, розничной торговлей), и частично обеспечивает финансовую поддержку. В результате акционной деятельности увеличиваются продажи, поскольку жители городов приобретают дополнительные товары для нуждающихся. Компания формирует лояльность к себе как к бренду в ходе вовлечения клиентов и своих сотрудников в благотворительную деятельность. При этом X5 Retail Group вовлекая своих сотрудников в роли добровольцев добавляет ресурсы в акцию, а за счет сотрудничества с федеральным фондом появляется возможность проведения единых акций во всех регионах.

Фонд продовольствия «Русь» отвечает за волонтерскую базу, логистику и распределение продовольственной помощи. Выгода для Фондапомощь от бизнеса в виде предоставления финансовых и нефинансовых ресурсов. Также НКО получает выгоду в виде эффективной работы на благо своей целевой группы. Эту работу можно оценить, измерить, что будет свидетельствовать о том, что НКО развивается, наращивает свою силу. Некоммерческая организация в партнерстве получает также дополнительные ресурсы для реализации своих общественно значимых инициатив.

Стоит заметить, что когда бизнес не может или не хочет решать острые социальные проблемы в одиночку, то он привлекает партнеров из некоммерческих организаций (по примеру сотрудничества Фонда продовольствия «Русь» и X5 Retail Group) и старается при этом заручиться поддержкой власти. В отличие от западной системы, где власть и бизнес формально не влияют на позицию друг друга, в российском обществе бизнес в своем отношении к социальным проектам очень прислушивается к мнению власти. Приведем конкретный пример. Целью создания Благотворительного фонда поддержки Уральского академического филармонического оркестра [10] являлось обеспечение устойчивого, хорошо спланированного поступления средств от партнеров. Были поставлены четкие задачисоздание системы привлечения благотворительных и спонсорских средств на деятельность филармонии.

При создании Благотворительного фонда поддержки Уральского академического филармонического оркестра параллельно с выстраиванием отношений с бизнесом - встала сложная задача убедить и власть в важности развития симфонического жанра и содержания хороше- 
го симфонического оркестра, что явилось бы высоким показателем высокого не только культурного, но и экономического уровня территории. В ответ на убедительные доказательства фандрайзера появился Указ Губернатора Свердловской области, в котором Уральский филармонический оркестр брался под покровительство губернатора и в котором был пункт, в котором поддерживалась инициатива создания Благотворительного фонда поддержки филармонического оркестра, который и был создан в течение следующего за указом месяца, что явилось важным знаком для бизнеса и для формирования Совета попечителей фонда, а фактически оркестра [11].

Естественно, что задача фандрайзера в условиях взаимодействия с бизнесом, должна сводиться к обеспечению постоянного партнерства в области разработки и реализации программ, т.е. сотрудничеству на постоянной основе. Вместе с тем, российский фандрайзер не всегда понимает, что его задачей является не только разовое привлечение средств на конкретные цели: социальный проект или акции, но, в первую очередь - заключение долгосрочного контракта. Фандрайзер не всегда прикладывает усилия, заранее не подготавливает проработанный и обоснованный проект, не умеет проводить сложные переговоры и находить баланс между отстаиванием собственных интересов и уважительным отношением к точке зрения бизнеса, и не всегда готов долго ждать, пока пройдут все согласования. В этих условиях ему необходимо быть экспертом в той проблеме, на решение которой запрашиваются средства и уметь излагать ее на понятном бизнесу языке, с аргументами, примерами, статистикой

При работе с бизнесом современный фандрайзинг должен четко понимать, что мотивы финансирования у крупного, среднего и мелкого бизнеса различны. В качестве примера можно привести организацию фанрайзинговой деятельности Общественного Благотворительного Фонда «Семьи детям» [12], ориентируясь на 3 категории бизнес-компаний, различающиеся по суммам поступлений. С каждой из этих категорий бизнес-компаний организация выстраивает работу по-разному (таблица 1).

Крупный бизнес в качестве партнера, как правило, выбирает достаточно известные и «благополучные» НКО. Стоит заметить, что социальная программа (в области здравоохранения, жилищных проблем и т.п.), которую предлагает фандрайзер той или иной крупной компании, должна быть связана с социально-экологическими потребностями выбранной организации. Руководители крупных компаний осознают тот факт, что разработка самостоятельного социального проекта, в большинстве случаев выходит неэффективной и слабой, отвлекающей их от непосредственного процесса производства и требующая от них выполнения несвойственных им функций (подобная деятельность не является функцией данного бизнеса). От бизнеса только потребуются материальные и нематериальные ресурсы.

Взаимодействовать с мелким и средним бизнесом, где денег меньше, несколько проще, так как эти компании нечасто поддерживают «социальные программы», и дают, в основном, деньги под небольшие проекты - «кейсы» на основе сложившихся личных отношений. Как правило, переговоры ведутся с первым лицом, который и принимает решения, и для достижения согласия порой достаточно бывает единственных переговоров, а текущие вопросы можно решить и по телефону. Однако, в своей работе российский фандрайзер не всегда может найти подход и к этому человеку, не всегда понимает мотивацию принимаемых им решений, а порой даже подготавливает и представляет ему не совсем грамотно составленный проект или запрос.

Сейчас крупные доноры стали более требовательны к фондам, которым они помогают. Им важно получить отчеты, чтобы узнать, действительно ли их деньги тратятся на те цели, на которые они их дают. Доноры стали тщательней выбирать тех, кому помогают. Люди, которые занимаются бизнесом, как правило, и от НКО хотят системности и прозрачности и, подобно акционерам в бизнесе, имеют право этого требовать. Однако механизмов контроля за деятельностью НКО у этой группы доноров пока нет, и поэтому чаще всего они пользуются той информацией, которую им дают в отчетах.

Говоря о фандрайзинговой деятельности НКО нельзя не затронуть еще одну категорию доноров - частные лица (владельцы собственных личных средств). Среди них могут быть люди разного социального склада, возраста, сфер интересов, привычек и убеждений. Основные мотивы участия частных доноров в благотворительности - желание помочь, норма жизни, подражание. 
Таблица 1. Основные направления фанрайзинговой деятельности Общественного Благотворительного Фонда «Семьи детям»

\begin{tabular}{|c|c|c|c|}
\hline $\begin{array}{c}\text { Категория/ } \\
\text { Объем поступлений }\end{array}$ & Мотивация & Особенности компаний & $\begin{array}{c}\text { Направления финанси- } \\
\text { рования }\end{array}$ \\
\hline $\begin{array}{l}1 \text { категория / дает мало- } \\
\text { бюджетные поступле- } \\
\text { ния - до } 50000 \text { рублей; }\end{array}$ & $\begin{array}{l}\text { Сочувствие руково- } \\
\text { дителей бизнеса той } \\
\text { аудитории, которой НКО } \\
\text { оказывает помощь. } \\
\text { Личное доверие руково- } \\
\text { дителю организации. }\end{array}$ & $\begin{array}{l}\text { Компании, представля- } \\
\text { ют в основном мелкий } \\
\text { и средний уральский } \\
\text { бизнес, готовый откли- } \\
\text { каться на небольшие } \\
\text { разовые акции, на вклад } \\
\text { в конкретную работу в } \\
\text { конкретном проекте }\end{array}$ & $\begin{array}{l}\text { На срочную помощь, кон- } \\
\text { кретные товары, вклад } \\
\text { в большие мероприятия } \\
\text { или мелкие акции }\end{array}$ \\
\hline $\begin{array}{l}2 \text { категория / дает сред- } \\
\text { ние поступления - от } \\
50000 \text { до } 500000 \text { рублей }\end{array}$ & $\begin{array}{l}\text { Благотворительная де- } \\
\text { ятельность, связанная с } \\
\text { развитием территории, } \\
\text { на которой работает ком- } \\
\text { пания совместно. с НКО, } \\
\text { продумывая план их про- } \\
\text { движения в том проекте, } \\
\text { который они поддержали. }\end{array}$ & $\begin{array}{l}\text { Средний и крупный } \\
\text { уральский бизнес, кото- } \\
\text { рый начинает задумы- } \\
\text { ваться о том, чтобы си- } \\
\text { стемно выстраивать свою } \\
\text { социальную политику, но } \\
\text { пока не готов финансово } \\
\text { вкладываться во что-то } \\
\text { масштабное. }\end{array}$ & $\begin{array}{l}\text { На средние и крупные } \\
\text { социальные проекты; } \\
\text { на создание социальной } \\
\text { рекламы; } \\
\text { на проведение значимых } \\
\text { праздников, форумов, } \\
\text { конференций. }\end{array}$ \\
\hline $\begin{array}{l}3 \text { категория / дает круп- } \\
\text { ные поступления - более } \\
500000 \text { рублей. }\end{array}$ & $\begin{array}{l}\text { Крупный бизнес всегда } \\
\text { знает, что он хочет полу- } \\
\text { чить от социальных про- } \\
\text { грамм, причем крупных } \\
\text { на основе имеющихся } \\
\text { документов, определяю- } \\
\text { щих и регламентирующих } \\
\text { эту область. } \\
\text { у компаний уже есть } \\
\text { сформированная соци- } \\
\text { ально активная позиция } \\
\text { и даже направления, } \\
\text { которые они поддержи- } \\
\text { вают (профилактика ВИЧ, } \\
\text { профилактика жестокого } \\
\text { обращения с детьми и } \\
\text { т.д.) Такие компании } \\
\text { выделяют определенную } \\
\text { сумму на благотворитель- } \\
\text { ные цели. }\end{array}$ & $\begin{array}{l}\text { Руководители и владель- } \\
\text { цы крупного бизнеса, } \\
\text { стратегия благотвори- } \\
\text { тельности которых совпа- } \\
\text { дает с работой НКО }\end{array}$ & $\begin{array}{l}\text { Средства на масштабные, } \\
\text { системные проекты; } \\
\text { обучение специалистов; } \\
\text { проведение исследований } \\
\text { в социальной сфере; } \\
\text { покупка недвижимости и } \\
\text { другие крупные приобре- } \\
\text { тения. }\end{array}$ \\
\hline
\end{tabular}

Приведем пример сбора частных имущественных не денежных пожертвований фонда продовольствия «Русь» от физических лиц по программе «ПРОДУКТОВЫЙ МАРАФОН». В рамках данного направления Фонд при партнерстве торговых компаний (ритейл) осуществляет сбор частных имущественных не денежных пожертвований (продовольственной и непродовольственной продукции) от физических лиц. Физические лица приобретают указанную продукцию в магазинах торговых компаний и передают в качестве пожертвований в адрес Фонда. Пожертвованная продукция безвозмездно передается Фондом благополучателям программы через партнерскую сеть НКО или напрямую.. Оказать помощь можно разными способами. Люди могут прийти купить продукты в магазинах и пожертвовать нам их прямо на территории магазинов.
Продовольственные марафоны проходят в самых разных известных магазинах.

Какие же сложности могут возникнуть у современного фандрайзера при работе с физическими лицами? Частные доноры, как правило, не склонны к стратегическому мышлению, им психологически проще принимать решение о пожертвовании, в случае если они понимают, что результат будет быстрым, измеряемым и конкретным (например, помощь на операцию, проведение конкретного спортивного мероприятия и др.). Для этой группы доноров все зависит от личной мотивации и темы, которая ему дорога. В своей деятельности современный фандрайзер не всегда понимает, что движет человеком, каковы его желания, и соответственно не всегда предлагает потенциальному донору то, что он хочет. В этом случае фандрайзеру важно рабо- 
тать с таким донором лично.

Таким образом, фандрайзеру нужно чутье и опыт, чтобы правильно работать с каждой категорией доноров. В случае взаимодействия с профессионально работающей командой НКО бизнес получает полноценного, равноправного партнера. Деятельность компании на благо местных сообществ способствует ее привлекательности как работодателя, улучшению связей с местным обществом и органами власти. Дополнительное упоминание бизнес-структуры как участника СП в средствах массовой информации, т.е. присутствие в информационном поле, также работает на развитие бизнеса.

В благотворительной поддержке нуждаются те, у кого появляются осознаваемые ими проблемы, то есть возникает некая неуспешность. Как показывает практика, российская ментальность предполагает готовность доноров к экстремальным действиям, им привычнее спасать (давать деньги голодным, больным, бездомным и т.д.), чем системно поддерживать благополучные и хорошо работающие организации, например, культуры и искусства, образования, спорта т.д. В практической российской фандрайзинговой деятельности даже появились выражения «сострадательной» и «созидательной» благотворительности.

На сегодняшний день потенциал взаимодействия коммерческого, некоммерческого и государственного секторов в фандрайзинговой деятельности остается недостаточно раскрытым. В результате и представители органов власти, и представители социальных департаментов и управлений, и бизнес-партнеры не всегда остаются довольными своими успехами в деле финансирования НКО. А это предполагает дальнейшее развитие теории и практики стейкхолдерского подхода в фандрайзинговой деятельности НКО.

\section{Библиографический список}

1. Бариленко В.И. Бизнес-анализ как новое направление аналитической работы // Сибирская финансовая школа. 2011. № 3. С. 32-35

2. Басова М.М. Основные критерии эффективности фандрайзинга в российских НКО / Экономические науки. 2019. № 6 (176).

3. Басова М.М. Особенности составления нефинансовой отчетности в социально ориентированных некоммерческих организациях // Вестник Московского университета им. С.Ю. Витте. Серия 1: Экономика и управление. 2017. № 3 (22). С. 50-53.

4. Возмилкина Е.Н. Фандрайзинг в социальной сфере // Научно-методический электронный журнал «Концепт».-2016. - Т. 11.- С. 4066-4070. [Электронный ресурс] - URL: http://e-koncept.ru/2016/86852.htm.

5. Корнеева И.Е. Фандрайзинг в российских некоммерческих организациях: результаты эмпирического исследования // Мониторинг общественного мнения: Экономические и социальные перемены. 2016 № 4 С. 48-66.

6. Общественное объединение и некоммерческие организации: деятельность и поддержка: монография / под ред. Т.Э. Петровой.-М.: ИНФРА-М, 2018. - 118 с

7. Официальный сайт Российского союза предпринимателей и промышленников [Электронный ресурс: http://media.rspp.ru]

8. http://bf.sistema.ru

9. https://foodbankrus.ru

10. https://www.sgaf.ru/fond/otchet

11. https://base.garant.ru/9302346/

12. http://semidetyam.ru 